\title{
O DIREITO AMBIENTAL COMO INSTRUMENTO PARA EFETIVAÇÃO DOS DIREITOS HUMANOS NO MUNICÍPIO DE CAMAÇARI-BA
}

\author{
THE ENVIROMENTAL LAW AS INSTRUMENT FOR EFETIVAÇÃO OF THE \\ HUMAN RIGHTS, IN CAMAÇARI/BA
}

\author{
EL DERECHO AMBIENTAL COMO HERRAMIENTA PARA TORNAR EFECTIVOS \\ DE LOS DERECHOS HUMANOS EN LA MUNICIPALIDAD DE CAMAÇARI - BA
}

Thiago Oliveira da Silveira ${ }^{1}$

O presente trabalho tem como objetivo apresentar o direito ambiental sob a perspectiva dos direitos humanos e de sua potencialidade para a transformação social. É visível a preocupação das pessoas com o ambiente, com o que as comunidades e o governo estão fazendo para amenizar os danos ambientais, os quais afetam o meio em que vivemos. Não menos importante, porém ainda não pacificado na doutrina e jurisprudência pátrias, é o entendimento da relação existente entre direitos interdependentes, quais sejam, os direitos humanos e os direitos ambientais, necessários uns aos outros para sua regular eficácia. No tocante ao acesso à informação ambiental, mostra-se evidente a carência, no município de Camaçari/BA, de dados relativos à questão ambiental e à preservação do meio ambiente, o que se revela numa incongruência, face à necessidade municipal de reverter o processo de degradação ambiental com o qual convive. Por fim, importante mencionar a proposta humanística da Universidade do Estado da Bahia (UNEB), Campus XIX, de transformação social através do ensino jurídico, pesquisa e extensão, a partir da observação da realidade político-sócio-ambiental na qual está inserida.

Palavras-chave: Direito ambiental. Direitos humanos. Questão ambiental. UNEB. Camaçari/BA.

The present work has as objective to present the enviromental law under the perspective of the human rights and it's potentiality for the social transformation. The concern of the people with the environment is visible, with what the communities and the government are making to reduce the environmental damages, which affects the place where we live. Not less important, however not yet pacified in the native doctrine and jurisprudence, it is the agreement of the existing relation between interdependent rights, which are, the human rights and enviromental laws, necessary ones to the others so their efficiency can be regulated. In regards to the access to the environmental information, the lack reveals evident, in the city of Camaçari/BA, relative data to the ambient question and the preservation of the environment, what leads to a incongruity, face to the municipal district necessity to revert the process of environmental degradation which it coexists. Finally, it's important to mention the humanistic proposal of the University of the State of the Bahia (UNEB), Campus XIX,

\footnotetext{
${ }^{1}$ Graduação em Direito (UNEB) - thiagoopiniao@yahoo.com.br
} 
of social transformation through legal education, research and extension, from the observation of the political-social-environmental reality in which it is inserted.

Word-key: Enviromental law. Human rights. Ambient question. UNEB. Camaçari/BA.

El actual trabajo tiene como objetivo para presentar la ley ambiental bajo perspectiva de los derechos humanos y de su potencialidad para la transformación social. La preocupación de la gente con el ambiente es visible, con lo que están haciendo las comunidades y el gobierno para aclarar encima de los daños ambiente, que afecta la manera donde vivimos. No menos importante, no obstante no todavía está pacificado en la doctrina y la jurisprudencia nativas, él es el acuerdo de la relación existente entre las derechas interdependientes, que son, los derechos humanos y las leyes ambientales, los necesarios a los otros sus regular eficacia. En respeto al acceso a la información ambiente, la carencia revela datos evidentes, en la ciudad de Camaçari/BA, relativos a la pregunta ambiente y la preservación del medio ambiente, qué si divulga en un incongrüência, cara a la necesidad municipal para invertir el proceso de la degradación ambiente que coexiste. Finalmente importante mencionar la oferta humanista de la universidad del estado de la Bahía (UNEB), del campus XIX, de la transformación social con la educación, búsquedas y la extensión legales, del comentario de la realidad político-socio-ambiente en la cual la insertan.

Palabra-llave: Ley ambiental . Derechos humanos. Pregunta ambiente. UNEB. Camaçari/BA.

\title{
1. CONSIDERAÇÕES INICIAIS
}

\begin{abstract}
Estamos diante de um momento critico na história da Terra, numa época em que a humanidade deve escolher o seu futuro. À medida que o mundo torna-se cada vez mais interdependente e frágil, 0 futuro enfrenta, ao mesmo tempo, grandes perigos e grandes promessas. Para seguir adiante, devemos reconhecer que no meio de uma magnífica diversidade de culturas e formas de vida, somos uma família humana e uma comunidade terrestre com um destino comum. Devemos somar forças para gerar uma sociedade sustentável global baseada no respeito pela natureza, nos direitos humanos universais, na justiça econômica e numa cultura da paz. Para chegar a este propósito, é imperativo que, nós, os povos da Terra, declaremos nossa responsabilidade uns para com os outros, com a grande comunidade da vida, e com as futuras gerações. (CARTA DA TERRA, 2000).
\end{abstract}

Presenciamos, nos tempos hodiernos, o ponto máximo das discussões, em escala global, acerca das questões ambientais e da necessidade de atuação conjunta entre os povos para amenização e/ou solução dos problemas concernentes ao meio ambiente.

As preocupações com o meio ambiente adquiriram máxima importância nas últimas três décadas do século XX e, a cada dia, ocupam um espaço cada vez mais 
relevante nas reflexões dos fóruns internacionais, nos meios de comunicação e nas inquietudes da sociedade civil, em virtude do alto risco de destruição da biosfera resultante da exploração desenfreada dos recursos naturais. Em todo o planeta, as espécies animais, vegetais ou minerais, estão em movimento acelerado de diminuição, já que a exploração é maior e mais veloz que a renovação das mesmas. Tal crise, associada à mudança climática e à destruição da atmosfera, afeta a vida de todos os seres vivos de modo alarmante e talvez irreversível.

Importante mencionar, no entanto, que, desde os remotos tempos, existiram normas voltadas para a tutela da natureza, mas não de forma expressa e abrangente como no presente. $E$ isto se deve ao desenvolvimento atual do mundo e aos diversos problemas de destruição do meio ambiente, que fizeram com que as nações adotassem um posicionamento para proteger a natureza, elaborando legislações de proteção ambiental.

Nesse contexto, o Direito Ambiental toma corpo, sendo considerado um conjunto de normas jurídicas que visam à preservação do meio ambiente, objetivando a melhoria da qualidade de vida humana.

Não obstante não possua um conceito preciso acerca de sua definição, tal como ocorre com o meio ambiente, o Direito Ambiental revela-se como uma matéria multidisciplinar, que busca adequar o comportamento humano ao meio que o rodeia, e que está essencialmente relacionado à preservação e efetivação dos direitos humanos, eis que constituído em bases humanísticas, antropocêntricas e voltadas às presentes e às futuras gerações.

\section{GENESE DO DIREITO AMBIENTAL: DE ESTOCOLMO A RIO 92}

A formação de uma consciência ambiental e as respostas e atitudes políticas e jurídicas surgiram após a Segunda Guerra Mundial, momento em que vários instrumentos para a proteção de águas doces e do mar foram ratificados.

No entanto, como dito anteriormente, as bases sólidas do Direito Ambiental emergiram a pouco mais de trinta anos, em alguns países industrializados onde a "corrida sem limites" por uma industrialização e pelo crescimento econômico incessante, com a conseqüente contaminação da água, do solo e do ar, tornou-se problemas nacionais e mundiais, que exigiam uma postura político-econômico-social capaz de conter os reflexos ocasionados pelo desequilíbrio crescimento $\mathrm{x}$ meio ambiente. 
$\mathrm{Na}$ década de 70, a Organização das Nações Unidas (ONU) promoveu a primeira grande reunião internacional sobre o meio ambiente, a Conferência das Nações Unidas sobre o meio ambiente humano, em Estocolmo. O resultado imediato desta Conferência foi a aprovação de uma declaração de princípios sobre o meio humano, denominada Declaração de Estocolmo. Nesse documento, de caráter meramente declarativo, foram abordadas as principais questões que preocupavam os países àquela época, recomendando-se critérios programáticos para a defesa do planeta e instituindo-se os princípios básicos do Direito Ambiental; o pilar orientativo dos inumeráveis tratados ambientais que surgiriam posteriormente estava, pois, formado.

Após a Conferência de Estocolmo, vários tratados multilaterais e bilaterais sobre o meio ambiente foram firmados, e, paralelamente, grande parte das Constituições passou a contemplar aspectos ambientais. Os progressos surgidos depois desta Conferência para uma melhor proteção do meio ambiente foram indubitáveis. Entretanto, ao fim da década de 80 , a humanidade encontrou-se diante de uma situação ambiental agravada, mais complexa e globalizada. Necessário era a conciliação entre a preservação do patrimônio ambiental planetário e o desenvolvimento sustentável ou ecodesenvolvimento. Neste contexto, surge, em 1987, o Informe Brundtland (Nosso Futuro Comum), inspirado na idéia de conciliar o desenvolvimento econômico dos povos com a salvaguarda dos valores ambientais.

No Brasil, o marco inicial das iniciativas voltadas à questão ambiental ocorreu com a Lei da Política Nacional do Meio Ambiente (Lei $n^{\circ} 6.938 / 81$ ), ainda vigente, que instituiu o SISNAMA - Sistema Nacional de Meio Ambiente, com o fim de harmonizar o meio ambiente e o desenvolvimento socioeconômico, mediante a adoção de condições para a exploração consciente dos recursos naturais, e considerando-se os interesses da segurança nacional e a proteção à dignidade da pessoa humana.

Posteriormente, a Constituição da República consagra esse entendimento, ao dedicar pela primeira vez um capítulo ao meio ambiente. Mais, busca a Lei Maior preservar não só o bem jurídico vida, como também a sadia qualidade de vida em um ambiente ecologicamente equilibrado, minimizando os riscos para as presentes e futuras gerações.

Uma vez apresentado o Informe Brundtland, a ONU convocou a Conferência sobre Meio Ambiente e Desenvolvimento, no Rio de Janeiro, em 1992. Desta 
conferência, conhecida como ECO 92, surgiu a Declaração do Rio sobre o Meio Ambiente e o Desenvolvimento, que ratifica e está fundamentada na necessidade de adotar um modelo econômico, social e político baseado no desenvolvimento sustentável.

Também foram adotados outros instrumentos normativos, como a Agenda 21, a Declaração Autorizada de Princípios sobre os Bosques e dois convênios de caráter jurídico obrigatório: o Convênio sobre a Diversidade Biológica e a Convenção sobre a Mudança Climática.

Em verdade, as declarações emanadas das Conferências de Estocolmo e do Rio estabeleceram diretrizes fundadas em condutas devidas pelos Estados e criadas dentro de uma ordem jurídica ambiental, a ser observada com espírito de solidariedade por todos os Estados e indivíduos, de modo a se atingir o tal logrado desenvolvimento sustentável.

Nesse sentido, mister colacionar:

Para um desenvolvimento socialmente sustentável é preciso alguns elementos como a participação, a organização, a educação e o fortalecimento das pessoas. O desenvolvimento sustentado não tem como foco a produção, mas sim as pessoas, logo deve ser apropriado não só aos recursos e ao meio ambiente, mas também à cultura histórica e aos sistemas sociais do local onde ocorre (NUNES, 2005).

\section{A PROTEÇÃO JURÍDICA DOS DIREITOS HUMANOS E SUA CLASSIFICAÇÃO}

Passada a era histórica da Segunda Guerra Mundial, a proteção e promoção dos direitos humanos (ou direitos do homem) representaram um dos fundamentos ideológicos da organização mundial que se fez necessária.

A Declaração Universal dos Direitos do Homem, aprovada em 1948 pela Assembléia Geral das Nações Unidas em 10 de dezembro de 1948, é o texto - base na proclamação e reconhecimento internacional dos direitos humanos. Essencialmente, seu escopo é assegurar a dignidade inerente a todos os membros da espécie humana mediante uma afirmação de direitos iguais e inalienáveis.

De modo amplo e global, os direitos dos homens e dos cidadãos estão resguardados em documentos como a Carta Internacional de Direitos Humanos, formada pela Declaração Universal dos Direitos do Homem, de 1948, e enriquecida pelos Pactos Internacionais de Direitos Econômicos, Sociais e Culturais de 1966 (direitos coletivos) e de Direitos Civis e Políticos de 1966 (direitos individuais). Ademais, outros regimes jurídicos de proteção especial configuram o sistema de 
proteção dos direitos humanos, tal como a Convenção Internacional sobre a eliminação de todas as formas de discriminação racial, de 1965; e a IIa Conferência Mundial de Direitos Humanos, ocorrida em 1993, em Viena, que sedimentou, em caráter universal, a necessidade de observação e preservação dos direitos humanos, bem como impôs a necessidade de reafirmação do compromisso e da responsabilidade de todos os Estados em promover o respeito universal e a proteção a todos os direitos humanos, mediante a promoção de um desenvolvimento que satisfaça as necessidade ambientais para garantir, entre outras medidas, a sobrevivência das gerações futuras.

A doutrina, por sua vez, oferece uma classificação para os direitos humanos resultante de um processo evolutivo desses direitos ao longo do tempo e baseada nas necessidades sociais. Tal classificação, assim, os divide em direitos de primeira geração (direitos civis e políticos), de segunda geração (direitos econômicos, sociais e culturais) e de terceira geração ou de solidariedade, na qual se incluiria, segundo a corrente doutrinária majoritária os direitos ao desenvolvimento, ao patrimônio comum da humanidade, à paz, ao meio ambiente saudável, à qualidade de vida, e à tutela dos interesses difusos.

No que diz respeito à legislação brasileira de cunho notadamente humanístico, destaque para Carta Magna de 1988, diploma que abarca importantes artigos referentes aos direitos humanos, quais sejam: o art.1ํㅡ, III, que protege a dignidade humana e a coloca como fundamento da República; art.3o, III, que impõe como objetivos fundamentais, entre outros, a erradicação da pobreza e da marginalização, a fim de reduzir a desigualdade social e regional; o art.5ำ, caput, que iguala todos perante a lei, e seu inciso III, que proíbe a tortura, o tratamento desumano ou degradante; o art. $6^{\circ}$, que determina a assistência aos desamparados; o art.193, que prevê como bases da ordem social o bem estar e a justiça social;o art.231, que reconhece aos índios sua organização social como um todo; e o art.225, que reconhece o direito de todos a ter um meio ambiente sadio e equilibrado.

O direito ao ambiente como um dos direitos fundamentais da pessoa humana é um importante marco na construção de uma sociedade democrática, participativa e socialmente solidária, sociedade esta consolidada durante um processo histórico caracterizado pelo reconhecimento das gerações de direitos humanos alhures mencionadas. 
O meio ambiente saudável e equilibrado, embora ainda não acolhido de forma expressa nos tratados internacionais sobre direitos humanos, está introduzido em muitos convênios regionais e, de forma mais categórica, nos documentos internacionais programáticos sobre meio ambiente. (ANTUNES, 1996)

Um meio ambiente sadio e ecologicamente equilibrado é um objetivo a ser reclamado, porque determina um desejo unânime e prioritário da sociedade e demais espécies: a vida. E pode ser considerado como um dos direitos humanos fundamentais, na medida em que a sua violação representa a violação do bem estar do indivíduo, produzindo reflexos destrutivos e diretos à existência do mesmo e, assim, à manutenção dos demais direitos atinentes à dignidade da pessoa humana.

\section{O DIREITO AMBIENTAL E OS DIREITOS HUMANOS: UMA LIGAÇÃO INTERDEPENDENTE}

Parece inquestionável a concepção de que o meio ambiente é essencial para que o ser humano possa gozar dos direitos humanos fundamentais, dentre os quais, o próprio direito à vida. Não obstante, o entendimento positivo e jurisprudencial para reconhecer-se a interdependência entre esses direitos ainda encontra obstáculos à uma pacificação.

A relação entre os direitos ambientais e os direitos humanos encontra-se pautada principalmente em dois aspectos. Numa primeira análise, a proteção do meio ambiente pode ser concebida como um meio para conseguir o cumprimento dos direitos humanos, tomando-se em conta que um direito ambiental infringido contribui diretamente para a violação dos direitos humanos à vida, à saúde, ao bem estar. O direito à vida é o mais fundamental de todos os direitos, já que sem vida, não há existência, e, portanto, não existem direitos nem obrigações. Neste contexto, o direito à vida poderia ser considerado como um pré-requisito, não somente para o direito ao meio ambiente, mas também para todos os demais direitos garantidos, inclusive os direitos que integram o que se entende por direitos humanos.

Em segundo lugar, os direitos ambientais dependem do exercício dos direitos humanos para terem eficácia, posto que é através do direito à informação, da tutela judicial, da liberdade de expressão, e da participação política na localidade em que vive, entre outros, que os indivíduos poderão reivindicar e possuir direitos ambientais. 
Por outra parte, a doutrina especializada mais relevante há algum tempo vem claramente fundamentando que o direito ao meio ambiente é um direito humano e simultaneamente propõe seu reconhecimento formal, ou seja, a positivização nos âmbitos internacional e nacional como forma de "fazer valer". Mas esta postura não parece ser majoritária, o que presume que tanto a teoria como o reconhecimento formal em convênios internacionais e ordenamentos jurídicos internos têm um longo caminho a ser percorrido.

(...) o objeto de proteção do meio ambiente, localizado no epicentro dos direitos humanos, deve ser levado em consideração toda vez que uma política, atuação, legislação sobre qualquer tema, atividade, obra etc. tiver que ser criada e desenvolvida. Isto porque, na medida em que possui como ponto cardeal de tutela constitucional a vida e a qualidade de vida, tudo que se pretende fazer, criar ou desenvolver deve antes passar por uma consulta ambiental, enfim, para saber se há ou não a possibilidade de que o meio ambiente seja degradado, e a preservação e qualidade da vida sejam colocadas em risco" (FIORILLO, 2009, p.60)

Inerentemente ao que possa significar o "direito a um meio ambiente adequado e equilibrado ecologicamente", assegurado no art.225 da Carta Magna de 1988, há uma implícita existência de uma forte ligação entre direitos humanos e meio ambiente que conduz à pergunta: quando se viola o direito ao meio ambiente, também são violados os direitos humanos? Apesar de tendências e proposições apresentadas, esta indagação, até o presente momento, não tem uma resposta consolidada.

No entanto, parece notória a íntima ligação e dependência existente entre os direitos humanos e os direitos ambientais, uma vez que estes dependem, necessariamente, da existência saudável daqueles direitos para terem sua existência e eficácia asseguradas, no meio social. Uma violação de qualquer um destes direitos invade o terreno do outro, constituindo um duplo desequilíbrio: o humano e o ambiental. Desse modo, o desequilíbrio ambiental é sempre o suficientemente grave para constituir uma violação aos direitos humanos.

\section{O ACESSO À INFORMAÇÃO AMBIENTAL COMO FOMENTO À TUTELA DOS DIREITOS HUMANOS}

A partir dos anos 70 do século $X X$, foram realizadas muitas conferências que apontaram para a necessidade de conscientização da população mundial para os riscos de desastres ambientais. Nessa época, as pessoas começaram a ter maior 
acesso a informações sobre o meio ambiente, e o movimento ambientalista ganhou roupagem maior com a criação de grandes ONGs ambientalistas, como o Greenpeace, estando as várias interferências destes grupos atuantes na seara ambiental pautadas em propostas de atuação diferenciadas, com o fim de melhorar a qualidade do meio ambiente e, portanto, das várias formas de vida existentes.

A informação ambiental encontra respaldo legal nos arts. 6을 $\S 3^{\circ}$, e 10 da Política Nacional do Meio Ambiente, sendo, ainda, corolário do direito de ser informado, previsto nos arts. 220 e 221 da Constituição Federal. Nota - se, ademais, a relação íntima entre aquela e o princípio da participação, que impõe a conduta de tomar parte em alguma coisa, agir em conjunto, para a defesa da Natureza.

Nesse sentido, traz-se à baila:

\begin{abstract}
A Constituição Federal de 1988, em seu art.225, caput, consagrou na defesa do meio ambiente a atuação presente do Estado e da sociedade civil na proteção e preservação do meio ambiente, ao impor à coletividade e ao poder público tais deveres. Disso retira-se uma atuação conjunta entre organizações ambientalistas, sindicatos, indústrias, comércio, agricultura e tantos outros organismos sociais comprometidos nessa defesa e preservação. (FIORILLO, 2009)
\end{abstract}

Atente-se para o fato de que tal previsão constitucional não representa um aconselhamento, mas sim, um dever da coletividade. Desse modo, estão todos, pessoas físicas ou jurídicas, vinculados legalmente a promoverem a tutela do meio ambiente, de modo que o produto de uma omissão participativa será um prejuízo a ser suportado pela própria coletividade, haja vista a natureza difusa que apresenta o direito ao meio ambiente.

O Direito Ambiental exige, por sua própria essência, que se "pense" em sentido global, mas também que se haja em âmbito local, adequando e compartilhando experiências para o apaziguamento e/ou solução dos problemas ambientais enfrentados. Nesse contexto, interessante apresentar, de modo direto, a realidade atual do município de Camaçari, Estado da Bahia. Localizado na região metropolitana de Salvador e, não obstante conviva com um processo de degradação ambiental preocupante e ocupe posição de destaque, em nível nacional, no tocante às exportações, à renda per capita por habitante e ao desenvolvimento industrial acelerado, o acesso a informações referentes ao meio ambiente e à atuação ambiental no município revela-se extremamente limitado. Apesar da necessidade cada vez maior de se fazer uma atuação conjunta e permanente entre o Poder 
Público e a sociedade de modo geral, poucos instrumentos são ofertados à coletividade para a reversão da realidade na qual está inserida, qual seja: a crescente poluição do ar e dos rios locais com matérias tóxicos resultantes da atividade industrial, sem que seja feito estudos sob o impacto que tais resíduos podem causar, em médio e longo prazo, à população; a degradação ambiental e o desmatamento de áreas para possibilitar a instalação de indústrias na cidade; a "desertificação" de várias áreas da cidade, produto da pequena arborização, entre outros.

Outrossim, vale frisar que, no que tange à temática ambiental, a sonegação de informações pode gerar danos irreparáveis à sociedade, eis que poderá prejudicar o meio ambiente, que além de ser um bem difuso, deve ser sadio e protegido por todos, inclusive pelo Poder Público, nos termos do art. 225, da Constituição Federal. Ademais, pelo inciso IV do citado artigo, o Poder Público, de modo a garantir o meio ambiente equilibrado e sadio, deve exigir estudo prévio de impacto ambiental para obras ou atividades causadoras de significativa degradação do meio ambiente, ao que deverá dar publicidade; ou seja, tornará disponível e público o estudo e o resultado, o que implica na obrigação ao fornecimento de informação ambiental.

Apesar das previsões legais quanto ao direito à informação ambiental e ao dever coletivo de fazer valer tal direito, as circunstâncias práticas que o cidadão encontra em Camaçari (e certamente em centenas de cidades brasileiras) funcionam como verdadeiros obstáculos à atuação social para proteção do meio ambiente, eis que, sem as informações necessárias, não será fácil para o indivíduo conhecer a fundo a questão ambiental e trabalhar isolada ou conjuntamente para amenizá-la.

\section{O ROMPER FRONTEIRAS COMO UMA META DA UNIVERSIDADE DO ESTADO DA BAHIA}

$\mathrm{Na}$ condição de instituição de ensino pública, gratuita e que objetiva a crescente qualidade, a Universidade do Estado da Bahia (UNEB), maior e melhor universidade estadual do norte e nordeste do país, de acordo com indicadores do Ministério da Educação, estabelece como uma de suas metas a atuação institucional que ultrapassa as fronteiras acadêmicas e, por conseguinte, se aproxima da 
realidade que circunda a circunda. Através dos seus 24 campi universitários, a UNEB se faz presente no interior e na capital do Estado, aumentando os alcances da educação e da formação profissional.

Especificamente no campus XIX (Camaçari), um projeto acadêmico singular está sendo desenvolvido no curso de bacharelado em direito, atribuindo-se ao ensino jurídico um caráter notadamente humanístico, que desprende o direito do seu positivismo e legalismo exacerbados e tradicionalmente perpassados pelas gerações de profissionais. Dá-se à formação do bacharel um enfoque nos direitos humanos, nos movimentos sociais, nas perspectivas de cidadania e, acima de tudo, no papel que se espera do profissional oriundo da universidade: o de um transformador da realidade social vivida, capaz não apenas de conhecer a legislação pátria, mas, principalmente, hábil a promover cidadania, interagir socialmente $\mathrm{e}$ promover melhorias substanciais ao meio circundante.

Nesse enfoque, investe a UNEB cada vez mais em pesquisa e extensão, alicerces que juntamente com o ensino, compõem a essência da verdadeira universidade pública, gratuita e de qualidade. Colóquios, projetos, seminários, encontros regionais e nacionais, ações comunitárias, entre tantas outras iniciativas, integram a política social-humanitária da universidade, que compartilha o saber científico com a sociedade, dando oportunidades a esta de se organizar e atuar cada vez mais em seu próprio benefício.

Os valores pregados na construção do saber jurídico e, portanto, na formação dos futuros bacharéis, em Camaçari, estão inseridos na perspectiva de ações conjuntas entre o estudante e a sociedade, seja através de fóruns e seminários acerca de temáticas importantes do cotidiano local, seja mediante a realização de pesquisas em áreas relevantes, como a referente ao Direito Ambiental (meio ambiente).

Assim, é através de uma série de iniciativas isoladas, mas motivadas por valores pacíficos entre $\mathrm{si}$, como direitos humanos e direitos ambientais, que a Universidade do Estado da Bahia tem se destinado a ultrapassar as fronteiras da sala de aula e chegar até à comunidade, exercendo uma função social que pode ter diferentes vertentes, mas certamente um único norte: possibilitar ao indivíduo ser um ator social, e não um mero espectador dos acontecimentos que o circundam.

\section{CONSIDERAÇÕES FINAIS}


A ênfase cada vez maior que é atribuída à temática ambiental e às suas repercussões sociais tem uma razão de ser: a humanidade vive um momento em que a preocupação com os problemas concernentes ao meio ambiente e à preservação deste perpassa pela necessidade inquebrantável de conscientização social para a tutela da natureza e de todas as formas que ela abarca na sua magnitude.

A proteção jurídica do meio ambiente é uma exigência já reconhecida. $E$ a evolução normativa que continua e intensamente se desenvolve vem delimitada por um imperativo fundamental de sobrevivência e de solidariedade: a responsabilidade pela preservação da natureza e, consequentemente, da vida para as presentes e futuras gerações.

A proteção ao meio ambiente pode ser considerada como um instrumento para se obter a satisfação dos direitos humanos, posto que na medida em que ocorre um dano ao meio ambiente, haverá desrespeito a outros direitos fundamentais do homem, como a vida, o bem estar, direitos estes internacionalmente reconhecidos.

O direito à vida, considerado como um direito universal do ser humano, visa estabelecer igualdade e segurança a todos os povos. Dessa forma, se todas as nações preservarem e contribuírem para um ambiente sadio e equilibrado, todos os povos estarão protegidos.

A realidade ambiental, em nível planetário, torna evidente que, mais do que nunca, faz-se necessária a conscientização social acerca das obrigações que cada indivíduo possui decorrentes do exercício de direitos assegurados nos tratados, diplomas e leis em geral. Assim, aquele que utiliza os recursos naturais deve estar ciente de que o uso racional de hoje é a garantia de utilização futura dos mesmos recursos.

Nesse contexto, sociedade em geral, poder público, iniciativa privada, instituições de ensino, entre tantos outros entes, exercem um papel crucial na divulgação de informações, na formação de seres humanos mais conscientes de seu papel em sociedade e no investimento crescente de políticas que versem sobre a tutela e preservação dos recursos naturais e, por conseguinte, do meio ambiente.

Assim é que, ao menos em Camaçari, a Universidade do Estado da Bahia já apresenta um rol de metas a serem cumpridas nos próximos meses, referentes à construção de redes de atuação e capacitação de atores sociais. Mediante a 
realização de eventos para um público-alvo composto por autoridades, estudantes e sociedade em geral, programas de capacitação em direitos humanos, investimento crescente em pesquisa, extensão e formação ampla e diversificada dos futuros profissionais, a UNEB desempenha o seu papel de planejar o global, mas atuar em nível local, exercendo a sua missão essencial de ser um instrumento de desenvolvimento e transformação da sociedade.

\section{REFERÊNCIAS}

ANTUNES, Paulo de Bessa. Direito Ambiental. 1a edição. Rio de Janeiro: Lumen Juris, 1996.

ARAÚJO, Thiago Cássio D’ávila . O direito à informação ambiental. DireitoNet, 15 nov. 2008. Disponível em: http://www.direitonet.com.br/artigos/exibir/3717/O-direitoa-informacao-ambiental, Acesso: 16 de janeiro de 2009.

BRASIL. Lei n. 6.938 - 31 ago.1981. Dispõe sobre a Política Nacional do Meio Ambiente, seus fins e mecanismos de formulação e aplicação, e dá outras providências. Brasília, DF: Subchefia para Assuntos Jurídicos, 1981.

BRASIL. Constituição (1988). Constituição da República Federativa do Brasil. Brasília, DF: Senado Federal, 2005. 75 p.

DHnet - Direitos humanos na internet. Disponível em: http://www.dhnet.org.br/direitos/sos/ecologia/index.html. Acesso em 10 dez.2008.

FIORILLO, Celso Antonio Pacheco. Curso de direito ambiental brasileiro. 10 ed.rev., atual. e ampl. São Paulo: Saraiva, 2009. 56p. 57p. 60p.

JURISAMBIENTE. Disponível em:

http://www.jurisambiente.com.br/ambiente/principios.shtm. 22.set.2008.

NUNES, Paulo H. Faria. Meio Ambiente e Mineração: 0 Desenvolvimento Sustentável. São Paulo: Juruá, 2005. 49p

SILVA, Sebastião B. Direitos ambientais também são direitos humanos. Disponível em:

http://www.dhnet.org.br/educar/academia/coloquio/meioambiente_sebastiao.html. Acesso em 09 fev.2009.

TOLOMEI, Lucas Britto. A Constituição Federal e o meio ambiente. DireitoNet, 15 nov. 2008. Disponível em: http://www.direitonet.com.br/artigos/exibir/2092/AConstituicao-Federal-e-o-meio-ambiente, Acesso: 16 de janeiro de 2009. 